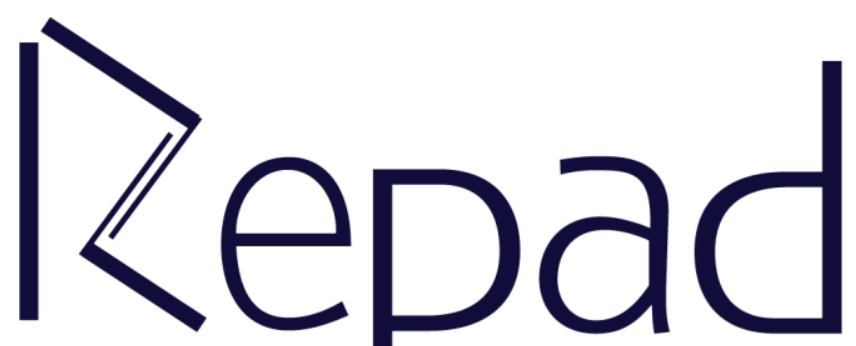

v. 5, n. 1, Janeiro-Abril/2021

Revista Estudos e

Pesquisas em Administração

(c) (i) This work is licensed under a Creative Commons Attribution 4.0 International License 


\title{
Benefícios da Atividade Turística na Manutenção da Saúde da Terceira Idade
}

\author{
Mirian Cristina Vidal da Rocha \\ https://orcid.org/0000-0002-7973-8766 \\ Universidade Federal Rural do Rio de Janeiro \\ Rio de Janeiro, Rio de Janeiro, Brasil \\ Ricardo Luis da Silva \\ rikardols@hotmail.com \\ https://orcid.org/0000-0003-3822-0298 \\ Universidade Federal Fluminense \\ Rio de Janeiro, Rio de Janeiro, Brasil \\ Iramir Gabrig Oliveira \\ https://orcid.org/0000-0003-0874-5675 \\ Centro Federal de Educação Tecnológica Celso Suckow da Fonseca \\ Niterói, Rio de Janeiro, Brasil \\ Andre Luís Faria Duarte \\ https://orcid.org/0000-0002-9862-6225 \\ Universidade do Grande Rio \\ Rio de Janeiro, Rio de Janeiro, Brasil
}

\section{RESUMO}

Este trabalho buscou como objetivo geral uma reflexão sobre a forma como as atividades turísticas podem interferir positivamente na saúde física, mental e emocional da população chamada terceira idade. Os objetivos secundários foram descrever aspectos que promovam avanços saudáveis à população idosa e averiguar ações estatais e governamentais quanto à saúde desse mesmo público por meio do Ministério do Turismo. A pesquisa se desenvolveu, em sua maior parte, adotando o Google Acadêmico e SciELO como bases de dados, assim como artigos e livros já publicados e disponibilizados na internet. Foram checados ainda como o Estado atua, principalmente através de medidas do próprio ministério setorial, tendo a saúde e a economia como pano de fundo, com o objetivo de dar conta tanto de pressões do mercado turístico, quanto a essa nova realidade que é o envelhecimento, cada vez mais evidente da população Os resultados deixaram visíveis que as atividades de lazer como um todo tem importante papel na promoção e manutenção qualidade de vida e saúde de idosos. Além disso, fica claro que muito ainda precisa ser feito e deve ser lapidado nessa relação entre poder público, mercado e idosos.

Palavras-chave: Turismo. Terceira idade. Saúde. Políticas públicas.

\section{Benefits of Tourist Activity in Maintaing the Elderly Health}

\section{ABSTRACT}

This research had as a general objective to reflect over how tourist activities can positively interfere in the physical, mental and emotional health of the population called 
elderly. The secondary objectives were to describe aspects that promote healthy advances to the elderly population and to investigate state and governmental actions regarding the health of that same public through the Ministry of Tourism. The majority of the research was developed using Google Scholar and SciELO as databases, as well as papers and books already published and available on the internet. The State role was also checked, mainly through measures taken by the sectoral Ministry itself, with health and the economy as a background, aiming at facing both the pressures of the tourism market and this new reality that is the aging process, increasingly evident in the population. The results made it visible that leisure activities play an important role in promoting and maintaining life quality and health for the elderly. In addition, it is seen that much remains to be done and should be refined in this relationship between government, market and elderly.

Keywords: Tourism. Elderly. Health. Public policies.

Submetido: 02/01/2021

Solicitação de Correções: 27/01/2021

Aceito: 30/01/2021

Publicado: 30/04/2021

\section{CONSIDERAÇÕES INICIAIS}

Um dos maiores destaques ocasionados pelo desenvolvimento global foi a ampliação do tempo de vida na Terra, resultado do progresso social e na saúde, ainda que de maneira desigual, entre diferentes países e contextos socioeconômicos. Chegar à velhice deixou de ser um privilégio de poucos indivíduos e passou a ser um fato comum também nos países mais pobres. Essa transformação trouxe, no entanto, um grande desafio para o século XXI. A qualidade de vida do idoso é importante não só para aumentar o seu tempo de vida, mas principalmente para promoção de inúmeros benefícios mentais, físicos, sociais e mentais.

Neste sentido, já é possível identificar algumas manifestações que demonstram que as atividades turísticas estão relacionadas a um bem viver diante do envelhecimento que não é só de ordem orgânica e ética, mas estética. Esta última traduzida muito mais no sentido mais no prazer, no desejo do estar-junto, no sentimento de pertença aos pequenos grupos do que a própria relação beleza e forma (ASHTON et al., 2015, p.3).

Além disso, o turismo deve ser entendido como direito fundamental do idoso destacando-se como importante elemento na construção de uma melhor qualidade de vida desse segmento que, ao participar das atividades propostas nos roteiros turísticos, melhora sua sociabilidade e relacionamento perante as situações do cotidiano. Ainda as atividades recreativas de animação, praticadas durante a experiência turística por idosos ou público em geral, tem o potencial de contribuir na saúde psíquica de seus praticantes, uma vez que estas atividades tem por objetivo uma melhor integração social e contribuem para a construção da autoestima trazendo alegria e sensação de felicidade ao indivíduo. 
Diante disso, a questão problema é: de que forma o turismo consegue resultar em uma melhora na vida de indivíduos da Terceira Idade?

\section{BENEFÍCIOS DA ATIVIDADE TURÍSTICA PARA O IDOSO E POTENCIALIDADES DO TURISMO DA TERCEIRA IDADE}

Até 2025, o Brasil será o sexto país com maior número de pessoas idosas do mundo, segundo a Organização Mundial da Saúde (OMS, 2005). Sem dúvida, a ciência tem buscado incessantemente aumentar o conhecimento sobre a vida humana e assim aumentar sua longevidade. $\mathrm{O}$ desenvolvimento de fármacos e tecnologias médicas permitem novos horizontes e criam uma nova etapa na vida dos seres humanos.

$\mathrm{Na}$ maior parte das nações, a lei estabelece que aos 65 anos de idade o indivíduo obtém o benefício da aposentadoria e a sociedade passa a enxergá-los como pertencentes ao grupo da terceira idade (OLIVEIRA, 2001). Kalache e Gray (1985) asseveram sobre o crescimento do número de idosos em quantitativo superior ao da população geral.

O envelhecimento leva o indivíduo a um processo contínuo e irreversível de alterações em seu organismo, com mudanças físicas, psicológicas e também sociais. Todavia, idosos vêm passando a explorar melhor o uso de seu tempo, muitas vezes antes disfrutados a sós ou com baixo convívio social, para então aproveitá-lo mais com mais autonomia e relacionamentos. Com isso, as atividades de lazer vêm desenvolvendo papel fundamental para a população idosa, na promoção do bem-estar e em sua própria vida cotidiana.

O usufruir do tempo livre com atividades de lazer motiva a formação de novos relacionamentos e uma visão diferente sobre a própria vida, melhorando a autoestima, se mostrando uma alternativa real para o aprimoramento da qualidade de vida das pessoas (MARTINS JÚNIOR, 2005).

Além do turismo, esportes individuais ou em equipe, atividades ao ar livre, música, dança, atividades individuais, sociais ou culturais, podem ser classificados como lazer, proporcionando um bem-estar físico e emocional.

O lazer é importante durante toda a vida, mas principalmente para as pessoas de idade avançada, pois apresenta-se como um valioso aliado no tratamento dos problemas típicos desta etapa da vida. Nesse sentido é importante salientar a abrangência do turismo (ASHTON et al., 2015).

O lazer é, na verdade, o tempo livre que o indivíduo pode usar da forma que desejar, desde que esse tempo resulte satisfação e felicidade. O mercado por sua vez utiliza o termo para induzir o indivíduo ao consumo.

Segundo Fromer e Vieira (2003), é importante entender a relação do idoso, enquanto cidadão e consumidor, com o turismo (fenômeno empresarial e social), para apontar novos caminhos e investimentos em produtos para a terceira idade, com criatividade e sensibilidade para trabalhar suas especificidades.

As atividades turístico-recreativas desenvolvidas especificamente para esse segmento, contribuem para a integração social, a melhora da autoestima e de aspectos emocionais e psíquicos em geral (ABREU; CASOTTI, 2018). De acordo com Ashton et al. (2015) o turismo, revelou a população idosa como um nicho importante não apenas de estudo, mas de efetividade em relação à possibilidade real de melhora na qualidade de vida, pois a partir de uma maior expectativa média de vida, com qualidade, ambos parecem se relacionar em perfeita simbiose. 
O turismo, apesar de ainda oferecer poucos produtos ao segmento terceira idade, é um dos setores com maiores possibilidades de explorar essa nova classe de consumidor. São consumidores que se sentem atraídos por viagens e lazeres de modo geral (FROMER; VIEIRA, 2003).

Soma-se a isso, o fato desse grupo ter muito mais tempo livre e a possibilidade de não ficar preso aos períodos de férias do trabalho ou dos filhos. Como explica Bacal (1992), para o turismo isso é extremamente importante na solução de um dos grandes gargalos do setor, a sazonalidade.

Segundo Fromer e Vieira (2003), é correto o entendimento de que o ingresso na terceira idade, em especial quando vem acompanhado da aposentadoria, implica em uma mudança significativa no dia-a-dia e na própria concepção de vida dos indivíduos. É também uma oportunidade para reexaminar os próprios conceitos e posicionamentos, para buscar novos horizontes e objetivos de vida para se beneficiar mais intensamente das possibilidades e alternativas que ainda estão por vir.

Brasileiros idosos com 60 anos ou mais fizeram ao menos 18 milhões de viagens somente no ano de 2015. O total cresceu $11 \%$ em quatro anos. O número de idosos dispostos a viajar pelos próximos seis meses soma 32\%. Por outro lado, a intenção dos turistas de até 35 anos caiu para 22\% (MTUR, 2017).

O turismo, por suas características, é mais que apenas um negócio, é um sistema complexo que envolve diversos elementos, ativando através da geração de empregos diretos e indiretos a economia local. A sazonalidade é parte também deste sistema, exigindo soluções cabíveis, tanto no que diz respeito aos picos de atividades, como também, e talvez principalmente, às épocas de pouca procura, fazendo com que o a atividade turística possa ser explorada adequadamente o ano todo. Para o idoso, o turismo pode ser uma excelente oportunidade de se realizar social, cultural, física e emocionalmente (SILVA, 2002). É importante observar que o turista da terceira idade não viaja apenas por ter tempo livre. Deseja o lazer, o prazer e concretizar sonhos (FROMER; VIEIRA, 2003).

É sensato, portanto, entender que a atividade turística, de modo geral, tem efeito positivo e importante na melhoria de qualidade de vida de todos os indivíduos, mas, em especial, para aqueles do grupo geralmente designado terceira idade. Com o acúmulo de tarefas e obrigações, mesmo na terceira idade, fase da vida comumente mais amena, as pessoas ainda têm muitas fontes de estresse como a violência, a poluição das cidades, as relações sociais com a família e com os amigos.

O turismo é uma excelente maneira de diminuir o estresse e tirar as pessoas das atribuições diárias, quebrando a rotina ao se afastarem, mesmo que por breve período, de deveres e obrigações. Uma viagem tem o potencial de fazer o viajante se voltar para si e refletir sobre a própria vida, deixando a rotina, mesmo que por pouco tempo.

Delboni (1997) e Lipp (2000) propõem possibilidades práticas de mudança do comportamento habitual para desvencilhar-se das tensões relacionadas ao estresse e evitá-lo. Tais autores sugerem o lazer, as viagens, novas amizades, o abstrair-se. Viajar traz, portanto, benefícios para a saúde emocional do grande público e em particular de idosos, já que propicia sensações positivas que se traduzem em autoconfiança e autoestima (ASHTON et al., 2015).

O passeio turístico é uma atividade indicada para melhoria da qualidade de vida de indivíduos da terceira idades por propiciar experiências diferentes do dia a dia e por demandar o envolvimento de mente e corpo, estimular o interesse pelo que é novo e 
pelo aprendizado, expandido a socialização e à inserção na comunidade em geral (ESPERANÇA et al., 2012).

Segundo Rocha e Glima (2000), entre os instrumentos disponíveis para o tratamento do stress também estão as técnicas de relaxamento, alimentação adequada, exercícios físicos regulares, repouso e sono apropriado às necessidades individuais.

Os estudos de Trentini et al. (2005) e Oliveira, Gomes e Oliveira (2006) sobre depressão revelaram que atividades físicas, de lazer e o relacionar-se com outras pessoas são importantes no tratamento e na prevenção da depressão associados ao tratamento medicamentoso. A interação social junto a exercícios físicos promove modificações fisiológicas e metabólicas nos praticantes (CORAZZA, 2005).

Segundo a Organização Mundial de Saúde, a prática das atividades físicas tem sido consistentemente associada beneficamente para a manutenção da funcionalidade, reduzindo os efeitos deletérios ocasionados pelo envelhecimento (OMS, 2005). Ajuda na socialização pois, com o tempo, é possível conhecer gente nova e diferente, o que é sempre bom para estimular a capacidade de se relacionar. Isso é notadamente importante para o grupo da terceira idade, já que está mais sujeito a sofrer com depressão ou isolamento social, assim, o trato com outras pessoas e com atividades afins, pode viabilizar amizades que poderão transcender a duração do passeio (ASHTON et al., 2015).

Dessa forma, o turismo atua como ferramenta na obtenção da saúde e qualidade de vida. Segundo Pereira et al. (2016), alguns estudos apontam, como resultado, um maior comprometimento do indivíduo até mesmo na adesão à terapêutica e no controle da pressão arterial.

Há que se notar, portanto, que os problemas inerentes à terceira idade, não podem ser considerados apenas pelo prisma da medicina avançada. É fundamental ter em conta, principalmente, a demanda por novas vivências que tragam realização, satisfação, prazer e integração com novas pessoas por meio de atividades culturais, sociais e turísticas.

Com relação ao lazer, a terceira idade desponta como uma fase singular da vida em se tratando de potencial possibilidade de usufruto desse tempo (DUMAZEDIER, 1976). A despeito de pessoas idosas, na maior parte das vezes aposentadas estas não sofrem mais as limitações impostas pela época de atividade no trabalho, apesar de ainda terem seus afazeres domésticos, cuidados dos filhos e netos. Contudo é indiscutível que esse grupo desfruta de uma porção maior de tempo livre, mais que a de outros segmentos sociais.

Dados recentes apontam que $16 \%$ dos brasileiros com 60 ou mais anos de idade desejavam viajar no mesmo ano da pesquisa realizada (MTUR, 2017). A expectativa de vida ativa está aumentando também no Brasil e, como consequência, mais pessoas idosas estão aptas a aderir ao lazer ativo e por maior período de tempo durante tal faixa etária, demandando assim novos produtos diferenciados e direcionados às suas necessidades (NASCIMENTO; SANTOS, 2016).

Segundo Fromer e Vieira (2003), os dados institucionais mostram que não se deve desprezar o potencial turístico para idosos, porém, ao mesmo tempo, não significa tutelá-los como grupo excepcional ou de privilegiados. Para Santos e Bertoldi (2012), ao se considerar a terceira idade como fase promissora para o desenvolvimento do turismo, os gestores responsáveis por satisfazer a esse público, antes de pensarem em disponibilizarem produtos e serviços, precisarão conhecer as características, os comportamentos, as necessidades, deste público para que possam entender as exigências 
e tendências características deste segmento do turismo. Nessa direção "para que os idosos possam viver mais e de forma mais proveitosa, muitas mudanças de caráter providencial devem ser tomadas pelo setor público, bem como pelo setor privado" (LIZ; RUSCHMANN; VERDINELLI, 2011, p. 6).

Como afirmam Liz, Ruschmann e Verdinelli (2011), o turismo para a terceira idade, deve ser capaz de proporcionar entretenimento, lazer e conhecimento, favorecendo também as interações sociais e a conquista de novas amizades minorando a solidão e consequentemente enriquecendo a qualidade de vida dessas pessoas.

E mais: "possuir produtos e serviços de alta qualidade apenas não é o suficiente. As empresas devem satisfazer consumidores distintos que podem escolher a partir de muitas ofertas de produto, no mercado global" (WEINSTEIN, 1995, p. 17). Dessa forma, para obter uma boa performance no mercado, a estratégica das empresas deverá ser o foco na eficiência, na identificação e análise do potencial cliente.

O turismo é uma indústria, um pilar para o desenvolvimento que envolva economia, política, cultura, história e sociedade, devendo ser examinado como uma atividade econômica em um mercado competitivo e em busca de sucessos econômicos para determinada região. Para que isso aconteça de maneira positiva, cabe aos profissionais de turismo decidir e saber quem são seus públicos-alvo e demandas específicas, assim como a classe de consumidores com poder aquisitivo capaz de pagar por um produto ou serviço, ou seja, quais consumidores desejam atender e quais produtos e serviços desejam ofertar. Sendo assim, a gestão turística de uma região depende basicamente de motivação e planejamento (MARTINS JÚNIOR, 2005).

Provavelmente alguns empresários do setor turístico ainda não avaliam os idosos como um grupo consumidor atraente, por vincularem a terceira idade a uma fase de debilidade física e de dependência financeira. Porém, segundo Fromer e Vieira (2003), o potencial desse público para desfrutar as viagens e lazeres de maneira geral é significativamente importante, pois possuem um perfil psicossocial de consumo, de interesse e de disposição física e mental para absorver novas experiências e conhecimentos. Valorizam prioritariamente o bem-estar e a satisfação pessoal. Não se importando em gastar mais para terem satisfeitas essas exigências (NASCIMENTO; SANTOS, 2016).

Evidentemente o idoso tem algumas particularidades no que diz respeito à fisiologia dos sentidos e à imunidade. Isso influencia diretamente suas percepções e a maneira com que tomam decisões ao consumir (OMOHUNDRO, 2004). Por esse motivo, o idoso precisa de um atendimento particularizado. Precisa de um ambiente harmonioso e hospitaleiro. Uma atmosfera de sutileza e gentileza, que atenda às suas expectativas.

Bacal (2003) alerta sobre a necessidade de se criar estratégias que possam minorar os efeitos do descompasso entre os "fluxos turísticos nas altas e baixas estações" reduzindo o efeito da sazonalidade nos resultados.

De tal modo, o setor de turismo aquece diversas outras atividades econômicas de produção de bens e prestação de serviços, envolvendo o trabalho de diversas categorias de profissionais e reunindo também dezenas de tipos de organizações que compõem e se somam ao produto turístico, tais como os ramos de agenciamento de viagens e operação turística, lazer, transporte turístico, organização de eventos, alimentação fora do lar, meios de hospedagem, turismo receptivo, espaços culturais, entre outros (SILVA ET AL., 2008). Nesse contexto, percebe-se o crescimento do segmento turístico da terceira 
idade, constituído por milhões de consumidores de diversas áreas, inclusive as do mercado turístico.

Segundo Silva et al. (2008), o tempo de vida cada vez maior, aliado ao desenvolvimento da economia mundial e ao desejo a moderno de viajar, pode significar um enorme impulso para o desenvolvimento da atividade turística. O turismo, seja entendido como fenômeno econômico ou sociocultural, será, sem dúvida, impactado positivamente em seus problemas relativos à sazonalidade, por essa nova força consumidora que, em sua maioria, é composta por pessoas com tempo para viajar durante todo o ano.

\section{A TERCEIRA IDADE COMO SEGMENTO DE MERCADO}

De acordo com a pesquisa Estilo de Vida e Consumo da Terceira Idade (CNDL; SPC BRASIL, 2018), muitos dos idosos brasileiros gastam hoje mais com o que gostam do que com aquilo que é considerado essencial. Dentre seus principais desejos de compra, por exemplo, estão roupas, calçados e viagens.

Uma maior quantidade de tempo disponível livre, deixa de ser um período improdutivo para se tornar parte das demandas da sociedade industrial. Um período no qual não se trabalha, não significa, necessariamente, que seja um período em que não se consuma.

Segundo o Ministério do Turismo (MTUR, 2015), o turismo da terceira idade é aquele destinado à melhoria da qualidade de vida destas pessoas e, por sua vez, auxilia nos problemas referentes à sazonalidade do turismo, estimulando o desenvolvimento de novos roteiros e atrações turísticas. Nesse entendimento, vislumbra-se o crescimento do segmento turístico da melhor idade, público que representa milhões de consumidores em diversos níveis.

Nesse sentido, é pertinente abordar a forma pela qual o indivíduo de terceira idade é compreendido, como cidadão e consumidor, pelo turismo.

Silva et al. (2008) assinalam a importância em indicar novos estímulos para os responsáveis do setor, atentando para a urgência de investimentos em produtos para esse público, sem tratá-lo como incapaz ou vulnerável.

Para Oliveira (2001), atualmente as pessoas têm chegado à terceira idade cada vez com mais saúde e estão viajando mais, inclusive, motivados por segurança, belezas cênicas e descanso nos destinos. As novas gerações dessa faixa etária apresentam características bastante distintas daquelas que surgiram duas décadas atrás (MARCELINO, 2002).

Outro fator a se considerar é que, em muitas regiões a renda média de idosos é maior aos rendimentos das demais famílias, sendo o Sudeste a região com mais elevado poder aquisitivo dessa população bem como maior número de idosos do país (IBGE, 2002).

Assim como quaisquer outros consumidores, os brasileiros da terceira idade desejam um bom atendimento, bom preço e qualidade no produto ou serviço que pretendem adquirir. A grande maioria se declara independente ao tomar decisões de compra e se dispõe a gastar mais com itens pessoais do que em coisas essenciais (CNDL; SPC BRASIL, 2018). Também reclamam de nem sempre encontrarem as melhores condições de consumo, seja pela dificuldade de encontrar serviços de entrega de determinados itens, seja por não terem disponíveis produtos específicos para essa 
faixa de idade. Relatam, também, dificuldade de ler rótulos com letras pequenas, por exemplo.

Souza (2006) ratifica essa ideia ao afirmar que o envelhecimento teve seu conceito invertido, representando hoje a idade do lazer. Aposentadoria, de acordo com a autora, já não significa recolhimento e descanso, mas sim viagem e lazer. O Turismo corrobora essa nova atitude e vem oferecendo opções para esse segmento.

A importância do idoso no crescimento da atividade turística no país está no fato de o indivíduo dispor, nesse estágio da vida, de mais tempo e melhor condição financeira para a resgatar projetos antigos ou para a elaboração de novos, Já não são tantas as suas obrigações profissionais e a família não mais exige tanta atenção. $\mathrm{O}$ lazer passa complementar suas necessidades.

Para atender a esse consumidor em potencial, as empresas do setor podem se segmentar escolhendo o tipo de cliente a que se dedicar, assim como o melhor produto a comercializar. A segmentação pode ser realizada por idade, renda, sexo, opção sexual, dentre outras. Se é melhor focar em quem viaja sozinho ou com a família ou se é mais interessante comercializar viagens pelo país ou exterior, por exemplo. Segmentar torna mais simples direcionar campanhas publicitárias, concentrar no que é prioridade e reunir consumidores de um mesmo perfil identificados por preferências homogêneas em um público-alvo específico de modo econômico (MAXIMIANO, 2004).

Uma das formas de se conhecer o mercado e seus consumidores é a utilização do mix de marketing, ou 4 P's do marketing, conceito ainda bastante atual proposto por Jerome McCarthy em 1960 e difundido por Philip Kotler, um dos principais estudiosos do marketing no mundo, considerado o pai do marketing. Esse mix é fundamental na criação de estratégias que objetivem agregar valor a um produto ou serviço diante de seus potenciais clientes, colocá-los de forma conveniente no mercado e promovê-lo de maneira que desperte o desejo nos consumidores. Segundo esse modelo, os 4 P's, princípios elementares de quaisquer estratégias de marketing, são definidos como: Produto, Preço, Praça e Promoção que, ao serem relacionados ao segmento nomeado como terceira idade, tema desse trabalho, burilados em sincronia, permitem que a marca/empresa alcance, de maneira mais eficiente, o público-alvo.

O conceito de produto, para Kotler (1998), assume que os consumidores favorecerão aqueles produtos que ofereçam mais qualidade, desempenho ou características inovadoras. Os profissionais de turismo, que pretendem explorar a fatia de mercado denominada terceira idade devem procurar conhecer os interesses característicos desse público, não só com relação aos destinos preferidos para as férias, por exemplo, mas também no que diz respeito a acomodação, locomoção, segurança, limpeza, alimentação; recreação, entretenimento, atendimento, cortesia etc. As pessoas procuram produtos que prometem determinados benefícios. Até mesmo os vouchers com suas cores e informações devem ser trabalhadas em função dos desejos desses consumidores. Kotler (1998, p. 28) define produto como "algo que pode ser oferecido para satisfazer uma necessidade ou um desejo"

De acordo com Kotler (1998), o preço é o único dos quatro P's do marketing que produz receita, os outros elementos geram custos, sendo também um dos elementos mais flexíveis desse mix, pelo fato de poder ser rapidamente alterado. O preço está diretamente relacionado ao volume de vendas do produto/serviço. Um aumento de preços pode reduzir a procura, assim como uma queda pode influenciar na demanda.

A pessoa incumbida desse departamento deve ser capaz de estabelecer um preço que seja competitivo junto à concorrência, ao mesmo tempo em que garante a sua 
própria sobrevivência no mercado. No caso do mercado turístico, locais de difícil acesso, por exemplo, podem justificar a cobrança de preços mais altos, baixa temporada ou grandes grupos de turistas condicionam menores preços. Para o consumidor, seja ele do grupo da terceira idade ou não, o preço deve oferecer a melhor relação custo e benefício.

A praça ou canal de distribuição é a maneira pela qual o produto chega até o consumidor e, de acordo com Kotler (2003, p. 52) "quanto maior a quantidade de canais, maior o alcance de mercado da empresa e mais altos os indicativos de vendas. Quaisquer ou quantos sejam os canais utilizados pela empresa, é preciso integrá-los [...]". Para Cobra (1992, p. 491) "a função básica de um canal de distribuição é escoar a produção de bens em geral, sejam bens de consumo, sejam bens industriais ou ainda serviços".

O encarregado por esse setor deve procurar conhecer os canais de informação e compras mais utilizados pelo grupo da terceira idade, a área geográfica que deverá ser coberta, e a logística necessária para apresentar o produto ou o serviço para que ele possa ser comprado e consumido. Enfim, o cliente necessita que a distribuição lhe seja conveniente.

A promoção de vendas constitui-se em de um conjunto de instrumentos de incentivo, geralmente de curto prazo, que objetiva encorajar a compra de forma mais rápida e/ou em maior quantidade de produtos/serviços específicos pelo público consumidor. Para o consumidor da terceira idade, assim como para qualquer outro consumidor se torna, sem dúvida, um grande atrativo. Kotler (1998, p. 386) argumenta que "é necessário antes de mais nada estabelecer os objetivos da propaganda. Precisam estar apoiados em bastante conhecimento sobre o mercado alvo e no próprio mix de marketing".

O mercado turístico despertou para esse público consumidor ancorado também por políticas públicas por meio do programa "Viaja Mais Melhor Idade". O programa tinha como objetivos: fomentar a inclusão social de indivíduos com mais de 60 anos, consolidar e desenvolver atividades regionais, além de ser um modo de diminuir a sazonalidade típica do mercado turístico na baixa temporada (MTUR, 2015). O MTur (2017) anunciou o fim do programa ao registrar que seus objetivos haviam sido atingidos com o sucesso. O programa foi lançado em 2007, tendo como resultado o aumento das taxas de ocupação dos serviços turísticos e, por consequência, a atenuação dos efeitos da sazonalidade no setor. Até sua finalização, em 2010, foram negociados cerca de 600 mil pacotes turísticos.

O desenvolvimento do turismo pode implicar em vantagens para os idosos no que diz respeito à preservação da sua saúde mental por meio da possibilidade de novas descobertas e ensinamentos, estímulo ao prazer e alegria e aproximação com novas culturas (MAZO, 2001). Para que se possa atender às expectativas desse público em relação ao turismo é necessário planejamento, com o objetivo de oferecer as melhores condições a serem desfrutadas. Trata-se da preparação dos atrativos, dos acessos, da infraestrutura básica, de todo o equipamento turístico, sendo ponto crucial para o desenvolvimento dessa atividade a capacitação dos profissionais envolvidos, direta e indiretamente.

Para Vilarinho e Scorsato (2009, n.p.), a atividade turística apresenta como especificidade as seguintes características: a) Intangibilidade: Não podem ser testados antes de serem comprados; b) Indivisibilidade: O produto é consumido e produzido simultaneamente; c) Variabilidade: A qualidade dos serviços depende de quem os 
proporciona e de quando, onde e como são proporcionados; d) Interdependência ou complementariedade: São necessários vários serviços para compor o produto turístico e, e) Perecibilidade: Os serviços são perecíveis e não podem ser estocados para vendas ou uso futuro.

O Turismo é considerado produto intangível por atender as necessidades mais variadas do indivíduo, como saúde, alegria, status, além de ser um serviço. Quando o turista se hospeda em um hotel, ele não adquire o hotel em si, mas os benefícios que este hotel proporciona. Uma pousada ou um restaurante, enquanto negócio, apresenta desafios, já que não se pode esquecer que, de um lado existem as necessidades, os desejos e o consumo dos clientes, geralmente turistas, e do outro lado, acontece a produção turística, ou seja, a prestação de serviços visando a satisfação e o encantamento, muitas vezes, ao se realizar sonhos planejados e entregar experiências incríveis.

Apesar do Turismo possuir uma indústria geradora de produtos turísticos, é importante não se ter sobre ele um olhar apenas econômico ou social, uma vez que ele tem impacto até mesmo sobre a saúde do indivíduo ao atender às necessidades mais diversas dos consumidores. Seus efeitos devem sempre ser encarados de modo holístico e humanizado.

Shostack (1977) afirma que um serviço é uma experiência vivida, e não pode ser armazenado, mas sim experimentado. O serviço se caracteriza por ser imaterial e não tangível. No entendimento de Gronroos (2003), o serviço em si é um fato complexo, com muitas variáveis distintas e únicas.

A oferta turística é caracterizada por todos os bens e serviços disponibilizados aos turistas, por um dado preço e um determinado período de tempo, conforme Lohmann e Netto (2008) e Lage e Milone (2000). Segundo Oliveira (2001), o mercado turístico é tudo aquilo que pode preencher o tempo dos turistas no lugar de visitação. Este último autor salienta, ainda, que o ganho que a economia local pode obter, equivale diretamente à sua competência para ocupar o tempo livre dos turistas. Ou seja, quanto maior for esta competência, maiores serão os lucros para mercado do lugar.

A importância de se estudar o comportamento do consumidor é abordada constantemente pelos autores de marketing. Uma sociedade marcada por tantas características, onde existe constante pressão para satisfazer suas necessidades e desejos no intuito de atingir o bem-estar, faz com que compreender as atitudes de indivíduos, em relação a compra, seja cada vez mais imperioso. De acordo com Kotler (2003), satisfação é a sensação de prazer ou decepção resultante da comparação entre o desempenho (ou resultado) percebido de um produto e as expectativas do comprador. Essa satisfação pode ser determinante para o sucesso das empresas.

As emoções integram o fenômeno do consumo, sendo parte da compra, das decisões e comportamentos após qualquer aquisição de um bem ou atendimento, no caso de serviços. Hosany et al. (2015) afirmam que as vivências são também uma das principais integrantes das experiências turísticas, podendo influenciar as escolhas e decisões de compra de serviços turísticos a serem relembradas antes, durante depois da viagem.

Porém, nem sempre as experiências são positivas em viagens, já que problemas podem ocorrer, originando emoções negativas. De acordo com Del Bosque e San Martin (2008), em turismo, os indivíduos podem experimentar emoções positivas ou não durante a estadia devido aos inúmeros contatos com os recursos do lugar. 
Fora isso, os sentimentos despertados enquanto o produto está sendo consumido, deixam rastros de afetividade na memória, que são acessados durante a avaliação da satisfação (COHEN; ARENI, 1991). Dessa maneira, as emoções servem para a aferição do nível de satisfação.

Kim, Woo e Uysal (2015), ao estudarem a experiência turística e qualidade de vida entre os turistas da terceira idade, verificaram que quanto maior a intensidade do envolvimento maior a percepção do valor e do sentimento de satisfação com a própria existência, demonstrando aí uma associação positiva entre a satisfação e lazer com a qualidade de vida de modo geral nesse segmento.

Portanto, as experiências e atividades turísticas podem afetar de maneira positiva a vida, seja no âmbito familiar, social, do lazer ou da cultura (UYSAL et al., 2016). Dessa forma, é primordial que os empresários do setor foquem cada vez mais na qualidade das experiências turísticas do grupo da terceira idade (KIM; WOO; UYSAL, 2015). A partir da premissa de que as futuras gerações de idosos deverão possuir um maior grau de escolaridade e, por associação, maior renda, esse é sem dúvida um mercado que deverá continuar promissor (MELLO; LIZ; VERDINELLI, 2015).

\section{TERCEIRA IDADE E POLÍTICAS PÚBLICAS DE TURISMO E SAÚDE}

Abarcado no âmbito nacional (lei federal n. 10.741/2003), o Estatuto do Idoso tem como finalidade normatizar direitos garantidos a idosos brasileiros. Sua vigência data de 2004, ampliando direitos previstos regulamentados pela nossa lei máxima (Constituição Federal de 1988), bem como, por outro dispositivo legal (lei federal $\mathrm{n}$. 8842/1994), firmando-se como instrumento importante na defesa da cidadania dos cidadãos e cidadãs da terceira idade (BRASIL, 2003).

Ainda conforme um de seus artigos: "o idoso tem direito à educação, cultura, esporte, lazer, diversões, espetáculos, produtos e serviços que respeitem sua particular condição de idade" (BRASIL, 2003, p. 19).

Mais de cem dispositivos do estatuto tratam dos seus fundamentos legais, incluindo direitos prioritários, bem como, questões relativas a transporte, liberdade e respeito à vida. Além disso, são especificadas também as atribuições das entidades de atendimento à categoria no que diz respeito a responsabilidades quanto a educação, cultura, esporte e lazer, saúde, alimentação, previdência social e habitação, tanto por parte do Estado, como da sociedade.

As políticas voltadas para a promoção, proteção e defesa dos direitos das pessoas idosas são transversais a várias áreas de governo. Pela mesma razão os compromissos do governo federal com o atendimento dessa população estão dispersos em diversos programas temáticos do PPA - Plano Plurianual - 2012/2015, em especial o Programa de Promoção e Defesa dos Direitos Humanos e também no âmbito da seguridade social, da mobilidade urbana, do trabalho e emprego, da acessibilidade e da educação (BRASIL, 2013, p. 70).

Publicado em 2006, o Pacto pela Saúde (portaria n. 399, GM, artigo 2), traz a aprovação das Diretrizes Operacionais do Pacto pela Saúde Consolidação do SUS, contemplando três tópicos em seu anexo II: Pactos Pela Vida, em Defesa do SUS e de Gestão. 
Ainda no mesmo ano, a Política Nacional da Saúde do Idoso é atualizada pela portaria n.2.528/2006, atualizando-a ao reconhecer que a população idosa tem suas peculiaridades e, para viabilizar ações de promoção da saúde, é indispensável conhecêlas e definir ações dirigidas às mesmas. A portaria tem como meta final garantir a "atenção à saúde adequada e digna para os idosos e idosas brasileiras" e incentivar a formulação de estratégias para a promoção da saúde (BRASIL, 2006).

Cabe resgatar o sentido de políticas públicas como movimentos estatais de aplicação de recursos, domínio e enfoque coletivo a determinadas populações, territórios ou mesmo atividades. São atos resultantes de pleitos da sociedade e não de iniciativas espontâneas do Estado. Emergem de uma conjuntura social, de debates entre correntes de grupos econômicos e políticos, classes sociais e outras forças da sociedade civil. A soma desses atos estabelece o que se compreende como políticas públicas (TEIXEIRA, 2002).

As políticas públicas influenciam diretamente no dia a dia da população propiciando melhor qualidade, oportunidades e uma maior participação social. Políticas públicas concretas têm como finalidade um amplo progresso sociocultural e econômico de uma cidade, Estado ou país. As reivindicações da sociedade chegam aos dirigentes públicos através da chamada Sociedade Civil Organizada (PEREIRA, 2008).

Conforme mencionado anteriormente, o programa Viaja Mais Melhor Idade (desenvolvido pelo MTUR com ênfase na experiência turística e no fomento do turismo doméstico para o segmento da terceira idade) teve um desempenho de êxito enquanto política pública nacional.

Em sua primeira edição (2007-2010), tal programa negociou em torno mais de meio milhão de pacotes de viagem (algo em torno de quinhentos milhões de reais). Já na segunda edição, encerrada em 2016, o programa ofereceu mais de 500 ofertas para 95 destinos brasileiros (MTUR, 2017).

A própria página institucional do Ministério do Turismo informa que as metas de 2013 foram atingidas, pois: “Atualmente, [à época] as empresas e os prestadores de serviços dispõem de canais de distribuição, ofertas de produtos e serviços turísticos diferenciados, bem como benefícios de maneira prática e ágil aos turistas brasileiros com mais de 60 anos" (MTUR, 2020, n.p.). E mais, no mesmo site pode ser verificado que os anos posteriores ao primeiro resultaram em expressivo crescimento dos destinos emissores e receptores. Conforme Carvalho e Silva (2014) em 2010, por exemplo, houve aumento significativo dos destinos emissores e estabilidade dos destinos receptores em relação ao ano anterior.

\section{POLÍTICAS PÚBLICAS EM TEMPOS DE PANDEMIA}

A sazonalidade turística é fenômeno conhecido e, de certo modo, previsível pelo mercado turístico. Ela representa as variações da demanda, que se repetem de forma padronizada em um determinado período de tempo. Estas interferem, positiva ou negativamente, no fluxo de caixa das empresas. O que não poderia ser previsto são as mudanças radicais provocadas em todo o mundo pela Covid-19 (FECOMÉRCIO, 2020).

Dentre as iniciativas tomadas pelo Governo Federal, através do Ministério do Turismo, após provocado por entidades ligadas ao trade turístico, foi o lançamento da campanha publicitária "Não cancele, REMARQUE". Lançada em 2020, a campanha orienta os turistas sobre a importância de não cancelar as viagens e pacotes turísticos 
durante a atual pandemia e incentiva o adiamento da reserva com a pousada, hotel, cia aérea, ou seja, para remanejar o passeio, a fim de reforçar a manutenção de negócios e postos de trabalho na área (MTUR, 2020b).

É importante registrar que, além de ter facilitado a destinação de cerca de 400 milhões de reais para financiamentos novos, o Ministério do Turismo tornou possível a concessão de empréstimos a partir do fundo setorial (Fungetur - Fundo Geral de Turismo). Junto ao Ministério da Justiça e Segurança Pública, o órgão elaborou ainda medida provisória n. 948/2020 que dispõe sobre o cancelamento de serviços, de reservas e de eventos dos setores de turismo e cultura em razão do estado de calamidade.

Grupo com maior risco de mortalidade devido à pandemia do novo coronavírus (COVID-19), a população idosa demanda projetos e medidas particulares com a finalidade de protegê-la por conta da sua vulnerabilidade maior frente a outros grupos geracionais.

Segundo Zwielewski et al. (2020), a principal medida aplicada pelos países afetados foi a quarentena, que é a separação e a limitação da mobilidade social de contaminados, com a intenção de diminuir o risco de infectarem outros indivíduos. A quarentena é tida como uma solução extrema, mas eficiente contra a propagação do vírus e a contenção de novos casos, principalmente entre os grupos de risco: maiores de 60 anos, pessoas que sofrem de complicações pulmonares ou de coração. A quarentena é diferente de isolamento, pois a mesma ocorre quando indivíduos infectados e confirmados para determinada doença são isolados com o objetivo de evitar a contaminação. Durante uma pandemia, a quarentena é o melhor procedimento, porém pode ser vivenciada pessoalmente como uma sensação desagradável, desconfortável ou dolorosa, até mesmo pelos familiares.

Tal cenário traz ao confinamento de famílias diversas emoções e sentimentos limitantes. Como enfrentamento, segundo Schmidt et al. (2020), no Brasil, foi publicada a Resolução CFP no 4/2020, normatizando serviços de terapia assistida e remota. Por outro lado, no mesmo ano, a Resolução CFP n ${ }^{\circ}$ 4/2020 autoriza a execução de trabalhos de psicologia mediados por tecnologia, seja individual ou coletivo, em caráter excepcional para casos de gravidade imediata ou risco à vida, com o intuito de reduzir parte dos reflexos negativos à saúde mental e psíquica do momento pandêmico atual.

\section{CONSIDERAÇÕES FINAIS}

Este estudo teve origem na observação de que a atividade turística possibilita praticamente tudo o que os profissionais da saúde aconselham para a promoção e manutenção da qualidade de vida, particularmente, daqueles indivíduos do chamado grupo da terceira idade.

$\mathrm{Na}$ busca por documentos que pudessem confirmar essa hipótese, foram encontrados números sobre a quantidade cada vez maior de idosos no mundo, sua melhor formação e nível cultural em relação às gerações anteriores, levando sempre em consideração uma maior exigência por melhor qualidade de atendimento e serviços.

Mudanças no comportamento do consumidor-turista idoso vêm sendo notadas, estudadas e trabalhadas por parte das empresas na reformatação e elaboração de produtos, desencadeando um mix de promoções, benefícios e serviços cada vez mais exclusivos para atender a essa demanda geracional de mercado. Muitos sites dedicados a esse segmento associam a atividade do turismo/lazer a benefícios para a saúde física e 
mental, à maior possibilidade de socialização, dentre outras, o que foi constatado pelos documentos levantados, principalmente no que tange ao fator mental/emocional.

A pesquisa também demonstrou que o governo tem se atentado à população idosa como um nicho de mercado de certa forma ao desenvolver políticas próprias como pano de fundo no fomento ao turismo, como no caso do "Estatuto do Idoso", e do implemento de programas de incentivo ao consumo do turismo através do Sistema $S$ (SESC, SESI, SENAI, SENAC, SEBRAE) e do programa Viaja Mais e Melhor, minorando os efeitos da sazonalidade no setor.

Contatou-se que há pouca literatura que trate dos efeitos benéficos da atividade turística para os idosos, quanto à sua qualidade de vida, saúde e disposição. Geralmente o foco é no potencial de consumo do idoso. Dessa maneira, é possível que o resultado alcançado por esse trabalho possa contribuir de alguma forma para futuras pesquisas sobre o assunto.

Outra limitação, sem dúvida, foi a paralisação total do mercado como um todo, devido à Covid-19, que desestruturou toda a sociedade mundial, impossibilitando ainda prognósticos e perspectivas.

As conclusões obtidas por esse trabalho sugerem, claramente, que o lazer necessita ser ponderado, quando se pensa na saúde física, mental e emocional dos idosos.

\section{REFERÊNCIAS}

ABREU, R. G.; CASOTTI, L. M. Turismo na Terceira Idade sob a Ótica da Transformative Consumer Research. Revista Turismo em Análise, v. 29, n. 2, p. 255 272, 2018. DOI: https://doi.org/10.11606/issn.1984-4867.v29i2p255-272. Disponível em: http://www.revistas.usp.br/rta/article/view/138507/153685.

ASHTON, S. G. M; CABRAL, S.; SANTOS, G. A.; KROETZ, J. A relação do turismo e da qualidade de vida no processo de envelhecimento. Revista Hospitalidade, v. 12, n. 2, p. 547-566, 2015. Disponível em: https://revhosp.org/hospitalidade/article/view/586/671. Acesso em: 25 jun. 2020.

BACAL, S. Lazer e o universo dos possíveis. São Paulo: Aleph, 2003.

BACAL, S. S. Turismo na terceira idade. Revista Turismo em Análise, v. 3, n. 2, p. 75-82. 1992. DOI: 10.11606/issn.1984-4867.v3i2p75-82. Disponível em: http://www.revistas.usp.br/rta/article/view/64159/66847.

BRASIL. Lei n. 10.741, de $1^{\circ}$ de outubro de 2003. Brasília: Senado Federal, 2003.

BRASIL. Portaria n. 2.528, de 19 de outubro de 2006. Brasília: Ministério da Saúde, 2006.

BRASIL. PPA 2012-2015: Agendas transversais - Monitoramento participativo. Pessoa idosa, ano base 2012. Brasília: MPOG, 2013.

CARVAlHO, F. C. C.; SILVA, C. C. B. O Turismo e a Renda dos Idosos: a experiência brasileira com o Programa "Viaja Mais Melhor Idade". Revista Anais Brasileiros de Estudos Turísticos - ABET, v. 4, n. 1, p. 25-34, 2014. Disponível em: https://periodicos.ufjf.br/index.php/abet/article/view/3040. Acesso em: 13 maio 2020. 
CNDL; SPC BRASIL. Estilo de Vida e Consumo na Terceira Idade. 2018. Disponível em: https://www.spcbrasil.org.br/wpimprensa/wpcontent/uploads/2018/09/SPC-Analise-Terceira_Idade_Estilo-de-Vida-e-Consumo.pdf. Acesso em: 12 mar. 2020.

COBRA, M. Administração de Marketing. 2. ed. São Paulo: Atlas, 1992.

COHEN, J. B.; ARENI, C. S. Affect and consumer behavior. ROBERTSON, T. S.; KASSARJIAN, H. H. (Eds.). Handbook of Consumer Behavior. Englewood Cliffs, N.J: Prentice-Hall, 1991. p. 188-240.

CORAZZA, D. I. Influência da Prática Regular de Atividade Física sobre Sintomas Depressivos em Idosos Institucionalizados. 2005. Dissertação (Mestrado em Ciências da Motricidade) - Instituto de Biociências do Campus de Rio Claro, Universidade Estadual Paulista, Rio Claro, 2005.

DEL BOSQUE, I. R.; SAN MARTÍN, H. Tourist satisfaction a cognitive-affective model. Annals of tourism research, v. 35, n. 2, p. 551-573, 2008. DOI: 10.1016/j.annals.2008.02.006. Disponível em: https://www.sciencedirect.com/science/article/abs/pii/S0160738308000273.

DELBONI, T. H. Vencendo o stress. São Paulo: Makron Books, 1997.

DUMAZEDIER, J. Lazer e cultura popular. São Paulo: Perspectiva, 1976.

ESPERANÇA, R. L. D.; CERCHIARI, E. A. N.; MARTINS, P. C. S. M.; ALVARENGA, M. R. M.; CANEVARI, S. C. Passeios turísticos como estratégia de prevenção e recuperação da saúde mental em idosos. Turismo Visão e Ação, v. 14, n. 2, p. 2012. 184-195, Disponível em: https://www.redalyc.org/pdf/2610/261056074004.pdf. Acesso em: 27 mar. 2020.

FECOMÉRCIO - Federação do Comércio do Estado do Ceará. Turismo perdeu R\$ 14 bilhões com crise do coronavírus, somente em março. 2020. Disponível em: https://www.fecomercio-ce.com.br/noticias/turismo-perdeu-r-14-bilhoes-com-crise-docoronavirus-somente-em-marco/. Acesso em: 18 jul. 2020.

FROMER, B.; VIEIRA, D. D. Turismo e Terceira Idade. Coleção ABC do Turismo. 2 ed. São Paulo: Aleph, 2003.

GRONROOS, C. Marketing: gerenciamento e serviços. 2. ed. Rio de Janeiro: Elsevier, 2003.

HOSANY, S.; PRAYAG, G.; DEESILATHAM, S.; CAUŠEVIS, S.; ODEH, K. Measuring Tourists' Emotional Experiences: Further Validation of the Destination Emotion Scale. Journal of Travel Research, v. 54, n. 4, p. 482-495, 2015. DOI: https://doi.org/10.1177/0047287514522878. Disponível em: https://journals.sagepub.com/doi/pdf/10.1177/0047287514522878.

IBGE - Instituto Brasileiro de Geografia e Estatística. Perfil dos idosos responsáveis por domicílios no Brasil. Rio de Janeiro: IBGE, 2002.

KALACHE, A.; GRAY, J. Health problems of older people in the developing world. PATHY, M. S. J. (Ed.). Principles and practice of geriatric medicine. Chichester: John Wiley \& Sons, 1985. p. 1279-1287. 
KIM, H.; WOO, E.; UYSAL, M. Tourism experience and quality of life among elderly tourists. Tourism management, v. 46, p. 465-476, 2015. DOI: 10.1016/j.tourman.2014.08.002. Disponível em: https://www.sciencedirect.com/science/article/abs/pii/S026151771400154X.

KOTLER, P. Administração de marketing: análise, planejamento, implementação e controle. 5. ed. São Paulo: Atlas, 1998.

KOTLER, P. Marketing de A a Z. São Paulo: Campus, 2003.

LAGE, B. H. G.; MILONE, P. C. Fundamentos econômicos do turismo. LAGE, B. H. G.; MILONE, P. C. Turismo: teoria e prática. São Paulo: Atlas, 2000. p. 25-37.

LIPP, M. E. N. Stress. 3 ed. São Paulo: Contexto, 2000.

LIZ, E.; RUSCHMANN, D.; VERDINELLI, M., A. Turismo e lazer para a terceira idade: perspectivas e desafios. SEMINÁRIO ANPTUR, 8, 2011, Camboriú - SC. Anais [...]. Balneário Camboriú: ANPTUR, 2011. Disponível em: https://www.anptur.org.br/anais/anais/files/8/130.pdf. Acesso em: 25 jun. 2020.

LOHMANN, G.; NETTO, A. P. Teoria do turismo: conceitos, modelos e sistemas. São Paulo: Aleph, 2008.

MARCELINO, N. C. Estudos de Lazer: uma introdução. 3 ed. Campinas: Autores Associados, 2002.

MARTINS JÚNIOR, O. S. Turismo e lazer para a terceira idade. 2005. Monografia (Especialização em Turismo, Cultura e Lazer) - Universidade de Brasília, Brasília-DF, 2005.

MAXIMIANO, A. C. A. Introdução à Administração. 6 ed. São Paulo: Atlas, 2004.

MAZO, G. Z. Atividade física e o idoso: concepção gerontológica. Porto Alegre: Sulina, 2001.

MELLO, C.; LIZ, E.; VERDINELLI, M. A. Acessibilidade e Segurança da pessoa idosa no espaço público. AMORIM, E.; SOARES, C.; TARLOW, P. (Orgs.). Segurança: Um Desafio para os Setores de Lazer, Viagens e Turismo. Tomar, Portugal: IPT, 2015.

MTUR - Ministério do Turismo. Marketing de Destinos Turísticos. 2015. Disponível em: $\quad$ http://www.turismo.gov.br/publicacoes/item/60-marketing-de-destinosturisticos.html. Acessado em: 18 jun. 2020.

MTUR - Ministério do Turismo. Sondagem dos consumidores e Intenção de viagem. Ano X, n. 83, 2017.

MTUR - Ministério do Turismo. Home Page. 2020. Disponível em: http://www.turismo.gov.br. Acesso em: 20 jun. 2020.

MTUR - Ministério do Turismo. Home Page. 2020b. Disponível em: http://www.turismo.gov.br/nao-cancele-remarque.html. Acesso em: 20 jun. 2020.

NASCIMENTO, F. S.; SANTOS, A. C. C. Os fatores motivacionais na prática da atividade turística na terceira idade: Um estudo a partir de um centro de convivência de idosos na cidade de Manaus. Revista de Turismo Contemporâneo, v. 4, n. 1, p. 1-22, 2016.

Disponível

em: 
https://periodicos.ufrn.br/turismocontemporaneo/article/view/7853/6958. Acesso em: 15 abr. 2020.

OLIVEIRA, A. P. Turismo e desenvolvimento: planejamento e organização. 3 ed. São Paulo: Atlas, 2001.

OLIVEIRA, D. A. A. P.; GOMES, L.; OLIVEIRA, R. F. Prevalence of depression among the elderly population who frequent community centers. Revista de Saúde Pública, v. 40, n. 4, p. 734-736, 2006. DOI: 10.1590/S0034-89102006000500026. Disponível em: https://www.scielo.br/scielo.php?pid=s0034$89102006000500026 \&$ script=sci_abstract\&tlng=pt.

OMOHUNDRO, D. L. Como as marcas devem ser apresentadas aos consumidores idosos. JONES, J. P. (Org.). A Publicidade na Construção das Grandes Marcas. São Paulo: Nobel, 2004. p. 350-367.

OMS - Organização Mundial de Saúde. Envelhecimento ativo: uma política de saúde. Brasília: OMS, 2005. Disponível em: http://bvsms.saude.gov.br/bvs/publicacoes/envelhecimento_ativo.pdf. Acesso em: 27 mar. 2020.

PEREIRA, P. A. P. Discussões conceituais sobre política social como política pública e direito de cidadania. BOSCHETTI, I. Política social no capitalismo: tendências contemporâneas. São Paulo: Cortez, 2008. p. 87-108.

PEREIRA, T. A.; SOARES, M. M.; RODRIGUES, S. M.; DIAS, C. A. Turismo de saúde e lazer: importância para a melhoria da qualidade de vida e das condições de saúde de indivíduos com doenças crônicas. SEMINÁRIO SOBRE ECONOMIA MINEIRA, 17, Diamantina. Anais [...]. Diamantina: CEDEPLAR-UFMG, 2016. Disponível em: https://diamantina.cedeplar.ufmg.br/portal/download/diamantina2016/236-398-1-RV.pdf

ROCHA, L. E.; GLIMA, D. M. R. Distúrbios psíquicos relacionados ao trabalho. FERREIRA JÚNIOR, M. Saúde no trabalho: Temas básicos para o profissional que cuida da saúde dos trabalhadores. São Paulo: Roca, 2000, p. 320-351.

SANTOS, R. A.; BERTOLDI, J. Os benefícios da atividade turística para a melhor idade. Revista científica eletrônica de turismo. Ano 9, n. 16, 2012. Disponível em: http://faef.revista.inf.br/imagens_arquivos/arquivos_destaque/zkjNKjxTzEICpwh_2013 -5-23-17-50-45.pdf. Acesso em: 9 jul. 2020.

SHOSTACK, G. L. Breaking free from product marketing. Journal of Marketing, v. 41, n. 2, p. 73-80, 1977. DOI: 10.1177/002224297704100219. Disponível em: https://journals.sagepub.com/doi/full/10.1177/002224297704100219.

SILVA, F. S. S. Turismo e psicologia no envelhecer. São Paulo: Roca, 2002.

SILVA, N. P.; FRANSCICO, A. C.; SCANDELARI, L.; THOMAZ, M. S. A qualidade de vida vista com o olhar da experiência: um estudo do segmento de turismo da melhor idade. ENCONTRO DE ENGENHARIA E TECNOLOGIA DOS CAMPOS GERAIS, 4, Anais [...]. 2008. Disponível em: http://www.4eetcg.uepg.br/oral/23_1.pdf. Acesso em: 24 abr. 2020.

SOUZA, T. R. Lazer, turismo e políticas públicas para a terceira idade. Revista Científica Eletrônica Turismo, v. 3, n. 4, p. 1-6, 2006. Disponível em: 
http://faef.revista.inf.br/imagens_arquivos/arquivos_destaque/AOFXoT8dR4BEfd6_20 13-5-20-16-24-21.pdf. Acesso em: 4 maio 2020.

TEIXEIRA, E. C. O papel das políticas públicas no desenvolvimento local e na transformação da realidade. Revista AATR. 2002. Disponível em: http://www.dhnet.org.br/dados/cursos/aatr2/a_pdf/03_aatr_pp_papel.pdf. Acesso em: 25 jun. 2020.

TRENTINI, C. M.; XAVIER, F. M. F.; CHACHAMOVICH, E.; ROCHA, N. S.; HIRAKATA, V. N.; FLECK, M. P. A. A influência dos sintomas somáticos no desempenho dos idosos no Inventário de Depressão de Beck (BDI). Brazilian Journal of Psychiatry, v. 27, n. 2, p. 119-123, 2005. DOI: 10.1590/S151644462005000200009. Disponível em: https://www.scielo.br/scielo.php?pid=S1516$44462005000200009 \&$ script=sci_abstract\&tlng=pt.

UYSAL, M.; SIRGY, M. J.; WOO, E.; KIM, H. L. Quality of life (QOL) and wellbeing research in tourism. Tourism Management, v. 53, p. 244-261, 2016. DOI: 10.1016/j.tourman.2015.07.013. Disponível em: https://psycnet.apa.org/record/201555263-028.

VILARINHO, P.; SCORSATO, S. Marketing de destinos turísticos. Brasília: MTUR, 2009.

WEINSTEIN, A. Segmentação de mercado. São Paulo: Atlas, 1995.

ZWIELEWSKI, G.; OLTRAMARI, G.; SANTOS, A. R. S.; NICOLAZZI, E. M. S.; MOURA, J. A.; SANT'ANA, V. L. P.; SCHLINDWEIN-ZANINI, R.; CRUZ, R. M. Protocolos para tratamento psicológico em pandemias: as demandas em saúde mental produzidas pela COVID-19. Revista Debates in Psychiatry - Ahead of print. 2020. Disponível em: http://www.hu.ufsc.br/setores/neuropsicologia/wpcontent/uploads/sites/25/2015/02/Protocolos-psic-em-pandemias-covid-final.pdf.

Acesso em: 25 jun. 2020. 